\title{
An In Vitro Chemosensitivity Test for Colorectal Cancer Using Collagen-gel Droplet Embedded Cultures
}

\author{
YASUMI ARAKI, HIROHARU ISOMOTO, ATSUSHI MATSUMOTO, ATSUSHI KAIBARA, \\ MASAFUMI YASUNAGA, KATSUMI HAYASHI, HIROYUKI YATSUGI \\ AND KEN YAMAUCHI \\ Department of Surgery, Kurume University Medical Center, \\ Kurume 839-0863, Japan
}

\begin{abstract}
Summary: This study evaluated in vitro assay for chemosensitivity test using a collagen-gel droplet embedded culture drug sensitivity test (CD-DST) for colorectal cancer. CD-DST was performed in 24 patients with Dukes B, C colorectal cancer. Primary cultures of tumor cell samples from $87.5 \%$ (21/24) patients with colorectal cancer were successful. The efficacy rates assessed by CD-DST of five anticancer drugs evaluated were : $60.4 \%$ for adriamycin, $58.9 \%$ for etoposide, $56.7 \%$ for cisplatin, $53.4 \%$ for 5 -fluorouracil, for $31.1 \%$ for mitomycin $\mathrm{C}$, and $9.5 \%$ for vindesine. The present study demonstrated the clinical usefulness of CD-DST in evaluating the response to chemotherapy in colorectal cancer.
\end{abstract}

Key words colorectal cancer, collagen-gel droplet embedded cultures drug sensitivity test

\section{INTRODUCTION}

Recently, the therapeutic results of colorectal cancer have been markedly improved by the development of the diagnostic and therapeutic techniques. The 5year-survival rate after curative resection has exceeded $80 \%$, but a poor outcome due to recurrence or metastasis is still observed in the remaining $20 \%$. Now that the surgical procedure has been established, further improvements in the outcome of colorectal cancer rely on adjuvant chemotherapies.

Various chemosensitivity tests have been developed. The nude mice method [1-3] proposed by Rygaard and Povlsens in 1969 was initially considered a useful model for predicting the antitumor effects in humans. However, this method has not been widely accepted because of its low efficiency, high cost, and a long time needed to obtain the results. Many in vitro chemosensitivity tests that can be performed quickly and at a low cost including the 3-[4,5-dimethylthiazol-2-yl]-2,5-diphenyltrazolium bromide assay (MTT assay) using a mono-layer culture $[4,5]$, human tumor clonogenic assay (HTCA) using a soft agar medium [6], thymidine incorpo- ration assay (TIA) [7,8], and succinic dehydrogenase inhibition test (SDI) [9] have since been developed, but they have not been put in wide use because of problems such the need for a large number of cells, a low success rate in primary culturing [10], and the effects of fibroblasts on the assay results [11]. The collagen-gel droplet embedded culture drug sensitivity test (CD-DST), which was used in the in vitro chemosensitivity test [11-13] reported in 1995 by Kobayashi et al., is suitable for primary culturing, which is difficult as a monolayer culture, can be performed with a small number of cells, and is free of the effects of fibroblasts, and its clinical usefulness in evaluating the chemosensitivity of various types of fresh surgical cancer specimens has been reported. The present study evaluated in vitro chemosensitivity testing using the CD-DST for colorectal cancer.

\section{MATERIALS AND METHODS}

\section{Primary tumor}

Fresh specimens were obtained from 24 patients 
who were diagnosed as having colorectal cancer. The specimens each weighed at least $0.3 \mathrm{~g}$.

\section{Preparation of the primary tumor cell suspension}

Each specimen was minced finely using a scalpel, suspended in Hanks' balanced saline solution (HBSS), and treated with a cell dispersion enzyme solution (EZ) of $0.1 \%$ (Nitta Gelatin, Japan) at $37^{\circ} \mathrm{C}$ for 3 hs. After digestion, each sample was centrifuged at $900 \mathrm{~g}$ for $3 \mathrm{~min}$ and filtered through $80-\mu \mathrm{m}$-pore nylon mesh. The recovered cells were washed in HBSS, suspended in PCM-1 medium (Nitta Gelatin, Japan), and incubated in a collagen gel-coated flask (Nitta Gelatin, Japan) in a $\mathrm{CO}_{2}$ incubator at $37^{\circ} \mathrm{C}$ for $24 \mathrm{hs}$. The collagen was then dissolved using a cell dispersion enzyme, and only the viable cells were collected by centrifugation.

\section{Collagen-gel droplet embedded culture [12,13]}

The collected viable cells were dispersed at a density of $1 \times 10^{5}$ cells $/ \mathrm{ml}$, in a collagen solution, which was a mixture of type I collagen (Nitta Gelatin), $10 \times \mathrm{F}-12$ medium and reconstitution buffer at a ratio of 8:1:1. Three droplets of the collagen-cell mixture were placed in the well of a six-well multiplate on ice, and allowed to gel in a $\mathrm{CO}_{2}$ incubator at $37^{\circ} \mathrm{C}$ for $1 \mathrm{~h}$. The final concentration was about $3 \times 10^{3}$ cells per collagen gel droplet. Three milliliter of DF medium (Nissui, Tokyo, Japan), containing $10 \%$ fetal bovine serum (Gibco, NY, USA) was overlaid, and then incubated in a $\mathrm{CO}_{2}$ incubator at $37^{\circ} \mathrm{C}$ overnight.

\section{Anticancer drugs}

Five anticancer drugs were added, at final concentrations of $1.0 \mu \mathrm{g} / \mathrm{ml}$ for 5-fluorouracil (5-FU), $0.03 \mu \mathrm{g} / \mathrm{ml}$ for mitomycin C (MMC), $0.02 \mu \mathrm{g} / \mathrm{ml}$ for adriamycin (ADR), for etoposide (VP-6), and 0.2 $\mu \mathrm{g} / \mathrm{ml}$ for cisplatin (CDDP) and incubated for $24 \mathrm{hs}$.

\section{In vitro chemosensitivity test}

After removal of the medium containing the anticancer drugs, each sample was washed with HBSS, overlaid with $4 \mathrm{ml}$ serum-free medium (PCM-2; Nitta Gelatin), and incubated for 7 days at $37^{\circ} \mathrm{C}$ with exchange of medium on the fourth day of incubation.

\section{Staining and fixation of cancer cells}

After incubation, neutral red (Nitta Gelatin) was added to each well at a final concentration of 50 $\mu \mathrm{g} / \mathrm{ml}$ and the colonies in the collagen gel droplets were stained for 2 hs. Each colony was fixed with
$10 \%$ neutral formalin buffer, washed with water and dried in air.

\section{Image analysis and evaluation}

The total volume of the tumor colonies, utilizing differences in the growth morphologies of the tumor cells and fibroblasts, was determined by an image analysis method described previously [2]. Evaluation of the anticancer drug effects was based on the ratio of the total volume of tumor colonies in the drugtreated group (T) to that of the colonies in drug untreated group (C). A T/C \% after culture for 7 days less than or equal to $50 \%$ was considered effective, a $\mathrm{T} / \mathrm{C} \%$ greater than $50 \%$ and less than or equal to $60 \%$ was considered borderline, and a $\mathrm{T} / \mathrm{C} \%$ greater $60 \%$ was considered not effective.

\section{RESULTS}

The in vitro sensitivity is shown in Table 1 . Figure 1 shows the growth morphology of human cancer cells and the results of neutral red staining in the primary culture. While cancer cells, which formed spherical colonies, were stained intensely, thin

TABLE 1.

CD-DST Procedure

\begin{tabular}{c}
\hline Fresh specimens \\
$\downarrow$ \\
Enzymatical digestion \\
$\downarrow$ \\
Incubation in collagen gel coated flask for 24 hours \\
Incubation in collagen gel droplet embedded culture \\
$\downarrow$ \\
Addition of the anticancer drugs \\
$\downarrow$ \\
Cultivation for 7 days \\
$\downarrow$ \\
Staining with neutral red \\
$\downarrow$ \\
Assessment using image analysis
\end{tabular}

TABLE 2.

Sensitivity of individual drugs, determined by the CD-DST, in colorectal cancer $(n=21)$

\begin{tabular}{cccccc}
\hline $5-\mathrm{FU}$ & $\mathrm{MMC}$ & $\mathrm{CDDP}$ & $\mathrm{ADR}$ & $\mathrm{VP}-6$ & $\mathrm{VDS}$ \\
$53.4 \%$ & $31.1 \%$ & $56.7 \%$ & $60.4 \%$ & $58.9 \%$ & $9.5 \%$ \\
\hline
\end{tabular}

In vitro drug sensitivity was defined as positive, when $\mathrm{T} / \mathrm{C}$ rate was $50 \%$ or less. 


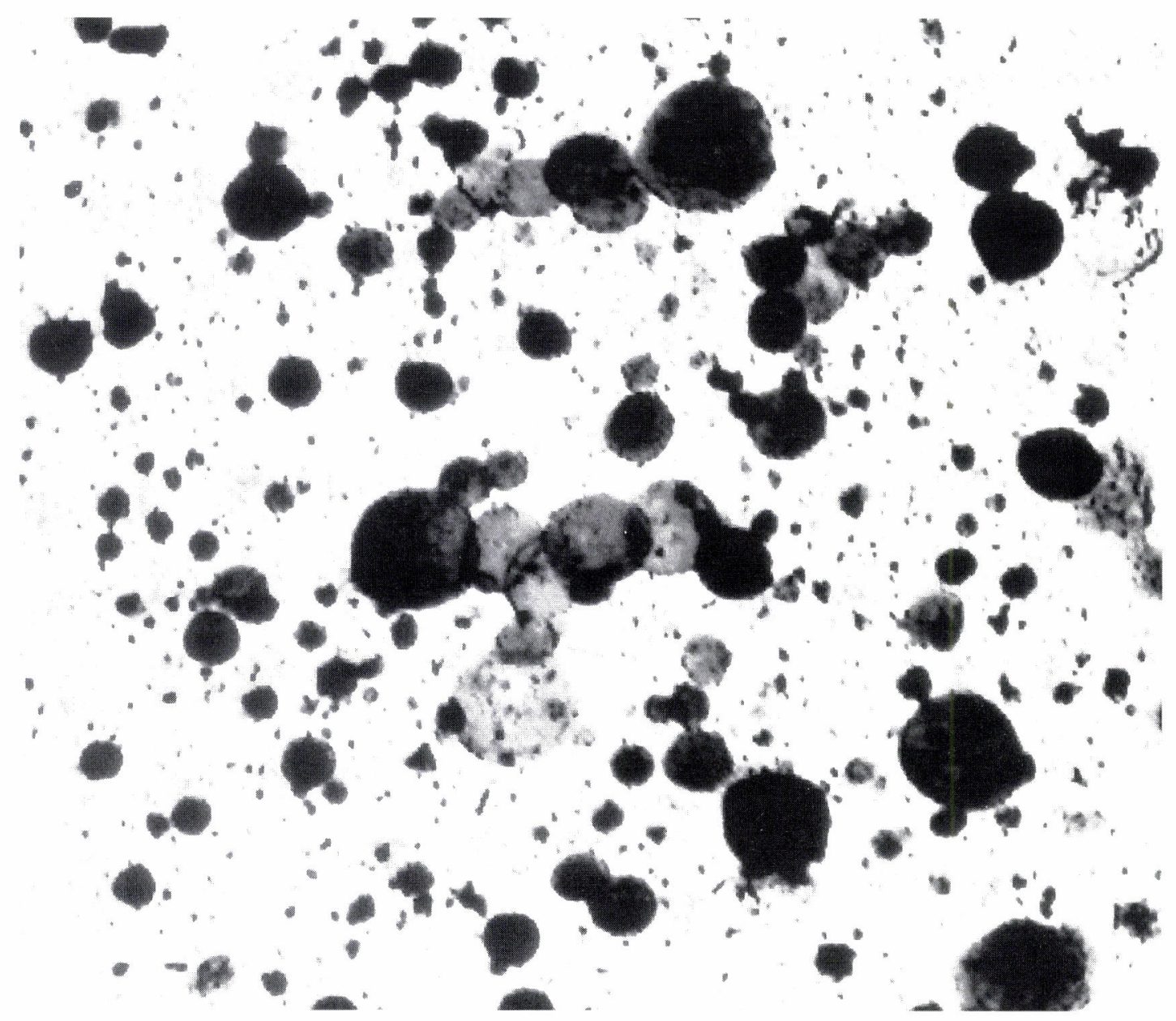

Fig. 1. With neutral staining in the growth morphology, tumor cells that formed spherical colonies were stained intensely, but thin fibroblasts were not stained.

fibroblasts were not stained, allowing pathological distinction of tumor cells from fibroblasts. The evaluable rate of CD-DST was $87.5 \%$ (21/24) for colorectal cancer cases. Against colorectal cancer, ADR showed that highest efficacy rate of $60.4 \%$, followed by VP-6 (58.9\%), CDDP (56.7\%), 5-FU $(53.4 \%)$, MMC $(31.1 \%)$, and $\operatorname{VDS}(9.5 \%)$. The sensitivity of colorectal cancer to 5-FU, CDDP, ADR, and VP-6 was significantly higher than to MMC and $\operatorname{VDS}\left(\mathrm{p}<0.01 ; \chi^{2}\right.$-test).

\section{DISCUSSION}

The aim of a chemosensitivity test in the treatment of cancer is to select effective anticancer drugs against cancers that are poorly sensitive and those that are sensitive but have developed resistance to standard regimens. Testing of chemosensitivity of a tumor before chemotherapy is considered to be important for improving the response rate. For this reason, various in vivo and in vitro chemosensitivity tests have been developed. However, the chemosensitivity tests developed to date had poor colony efficiency, required a large number of tumor cells, and their results are affected by fibroblasts.

CD-DST, in which the cells were embedded and cultured in $30-\mu 1$ collagen-gel droplets, has the following clinical advantages: 1) The assay could be performed with a relatively small number of cancer cells $\left(3 \times 10^{3}\right.$ cells per $30-\mu 1$ drop), 2) primary cultures of human tumor cells retaining the same morphology as in the living body could be grown three-dimensionally at a high success rate, 3) the results of exposure of the cells to the anticancer agents could be represented as the conventional area under the curve, and the growth of fibroblasts could be controlled. Furthermore, the results of the administration of 5-FU, MMC, CDDP, etoposide, and ADR at the same circulating concentrations as in the clinical administration to nude mice transplanted 
with 13 human cancer cell lines were correlated with the results of CD-DST using the same cell lines $(r=0.84)$; antitumor effects observed in in vivo nude mice sensitivity tests were significantly correlated with the results of CD-DST [15]. Moveover, the success rate of the test was high at $80 \%$ or above $[13,16]$. In the present study using CD-DST, also, successful primary cultures were in $21(87.5 \%)$ of the 24 cases of colorectal cancer, suggesting high clinical usefulness of the test. In addition, serum-free culture medium used for 7-day cultures following exposure to anticancer drugs showed continued inhibition of fibroblast proliferation. Concerning the relationship between the growth morphology and the results of neutral red staining in primary cultures of cancer cells, cancer cells that formed spherical colonies were stained intensely while thin fibroblasts were not stained, allowing pathological distinction between tumor cells and fibroblasts.

All patients underwent surgery and postoperative chemotherapy. At this point, the assay and clinical efficacy cannot be evaluated, and the association between clinical responses of colorectal cancer and the results of CD-DST remains to be investigated. However, the report that the results of CD-DST in primary cultures of surgically obtained cancer cells and their clinical response rates to various drugs were significantly correlated in 189 patients with lung cancer and 99 patients with breast cancer [17] suggests the potential usefulness of CD-DST.

\section{REFERENCES}

1. Osieka R, Houchens DP, Goldin A, and Johnson RK. Chemotherapy of human colon cancer xenografts in athymic nude mice. Cancer 1977; 40:2640-2650.

2. Countenay VD, and Mills J. An in vitro colony assay for human tumors grown in immune-suppressed mice and treated in vivo with cytotoxic agents. Br J Cancer 1978; 37:261-268.

3. Rygaard J, and Povlsen CO. Heterotransplantation of a human malignant tumour to nude mice. Acuta Pathol Microbiol Scand 1969; 77:758-760.

4. Mosmann T. Rapid colorimetric assay for cellular growth and survival: application to proliferation and cytotoxicity assays. J Immunol Method 1983; 65:55-63.

5. Fruehauf JP, Myers CE, and Sinha BK. Synergistic activity of suramin with tumor necrosis factor alpha and doxorubicin on human prostate cancer cell lines. J Natl Cancer Inst 1990; 82:1206-1209.

6. Salmon S, Mamburger A, and Soehnlen B. Quantitation of differential sensitivity of human tumor stem cells to anticancer drugs. N Engl J Med 1978; 298:1321-1327.

7. Tanigawa N, Kern DH, Hisaka Y, and Morton DL. Rapid assay for evaluating the chemosensitivity of human tumors in soft agar culture. Cancer Res 1982; 42:21592164.

8. Kern DH, Drogemullar CR, Kennedy MC, Hildebrand $\mathrm{SL}$, Tanigawa $\mathrm{N}$ et al. Development of miniaturized, improved nucleic acid precursor incorporation assay for chemosensitivity testing of human solid tumors. Cancer Res 1985; 45:5436-5441.

9. Kodo $\mathrm{T}$, Imamura $\mathrm{T}$, and Ichihashi $\mathrm{H}$. In vitro test for sensitivity of tumor to carcinostatic agents. JPN J Cancer Res 1966; 57:113-121.

10. Shomarker R, Wolpert DM, Kern DH, Lieber MM Makuch RW et al. Application of a human tumor colonyforming assay to new drug screening. Cancer Res 1985; 45:2145-2153.

11. Yang J, and Nandi S. Growth of cultured cells using collagen as substrate. Int Rev Cytol 1983; 81:249-286.

12. Koezuka M, Kondo N, Kobayashi H, Hara S, Yasutomi $M$ et al. Drug sensitivity test for primary culture of human cancer cells using collagen gel embedded culture and image analysis. Int J Oncol 1993; 2:953-959.

13. Kobayashi H, Tanisaka K, Kondo N, Mito Y, Koezuka $M$ et al. Development of new in vitro chemosensitivity test using collagen gel droplet embedded culture and its clinical usefulness. Jpn J Cancer Chemother 1995; 22:1933-1939.

14. Inaba M, Tashiro T, Kobayashi T, Sakurai Y, Maruo K et al. Responsiveness of human gastric tumors implanted in nude mice to clinically equivalent doses of various antitumor agents. Jpn J Cancer Res 1988; 79:517-522.

15. Kobayashi H, Tanisaka K, Doi O, Kodama K, Higashiyama $\mathrm{M}$ et al. An in vitro chemosensitivity test for solid human tumors using collagen gel droplet embedded cultures. Int J Oncol 1997; 11:449-455.

16. Tangawa $N$, Kitaoka $A$, and Yamakawa $M$. In vitro chemosensitivity testing of human tumors by collagen gel droplet culture and image analysis. Anticancer Res 1996; 16:1925-1930.

17. Bakowski MT, and Crouch JC. Chemotherapy of nonsmall cell lung cancer: a reappraisal and a look to the future. Cancer Treat Rev 1983; 10:159-172. 